\title{
Poética, documento, memória Ballet, de Brodovitch
}

\author{
João Carneiro
}

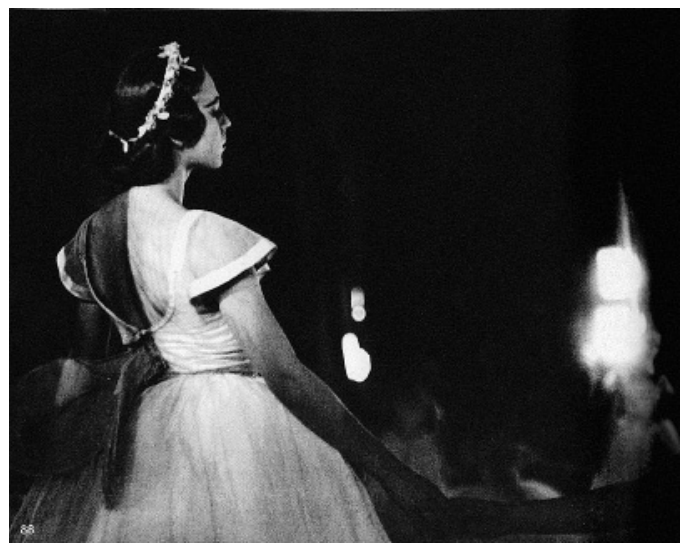

Em 1945 foi publicado em Nova lorque o livro Ballet, de Alexey Brodovitch. 0 editor foi J.J. Augustin, e a tiragem não excedeu os quinhentos exemplares. 0 livro tinha 144 páginas e 104 ilustrações - fotografias a preto e branco. Nesse ano, Ballet foi distinguido com o Book of the Year Award, do Instituto Americano das Artes Gráficas (American Institute of Graphic Arts).

Alexey Brodovitch nasceu em Ogolich, na Rússia, em 1898. 0 pai era físico e psiquiatra, e foi dele que Alexey recebeu a primeira máquina de fotografar. Com ela fez as primeiras fotografias, de prisioneiros de guerra japoneses, durante a guerra russo-japonesa, assim como retratos de doentes internados no hospital onde trabalhava o seu pai.

Alexey Brodovitch teve uma educação sofisticada e cosmopolita, e a sua primeira língua foi o francês. $\mathrm{Na}$ sequência da revolução de 1917, a família exilou-se em França, e a certa altura Alexey Brodovitch encontra-se em Paris, a viver com a sua mulher Nina, e sem dinheiro. Pretende, também, seguir uma carreira nas artes plásticas, nomeadamente enquanto desenhador e pintor. Começa por pintar paredes, e passa a pintar cenários para os espectáculos de Diaghilev. Conhece Picasso, Derain, Christian Bérad, Alexander Benois, Anna Pavlova, Nijinsky Massine.

Em 1930 vai para os EUA, e a partir de 1934 é director artístico de Harper's Bazaar, onde ficará durante vinte e cinco anos. Em 1950-51 cria três números de Portfolio, uma importante revista de artes gráficas; criara antes o
Design Laboratory, que será um centro de trabalho e encontro de artistas fotógrafos, como Richard Avedon, Robert Frank e Lisette Model.

Entre 1935 e 1937 Alexey Brodovitch fotografa várias companhias de Ballets Russes, provavelmente em Nova

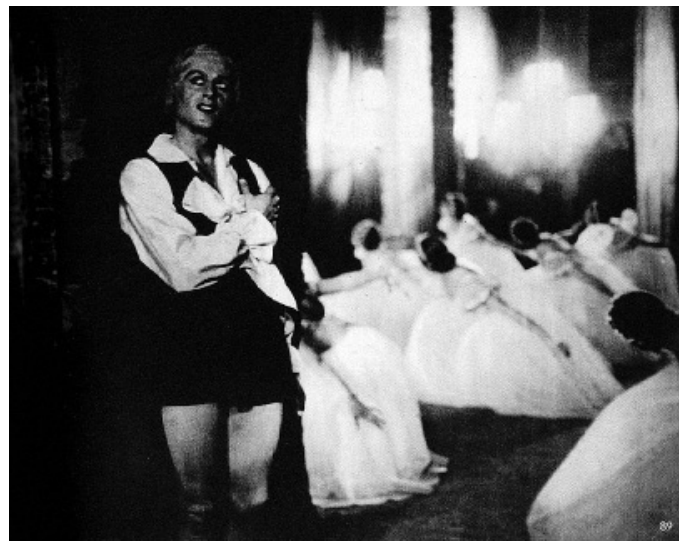

lorque. Diaghilev morrera em 1929, e estas companhias são uma espécie de herança e de tentativas, mais ou menos conseguidas, para continuar a fazer viver, durante alguns anos, aquilo que ficou conhecido como Ballets Russes. Em 1945, como refere Edwin Denby na sua "Introdução", "Ballet Russo" já designa com mais propriedade uma realidade ligada à União Soviética, enquanto "Ballets Russes" é uma expressão que remete "para o estilo de Diaghilev, que provavelmente nunca mais veremos" (trad. minha'). Alexey Brodovitch fotografa uma realidade que, em 1945, é relativamente estranha, nomeadamente na relação com aquilo que é já a dança e o ballet nos EUA. Os Ballets Russes de Alexey Brodovitch ou, dito de outra maneira, as fotografias que Alexey Brodovitch fez destes Ballets Russes são um exercicio de preservação de memória, uma lembrança. Como escreve Edwin Denby, elas têm o "carácter desastrado, a manipulação catastrófica de lembranças sentimentais". São fotografias com um carácter imediato, que pretendem captar uma ideia de dança, de execução, de um tipo particular de trabalho. São muito pouco, ou nada mesmo, convencionais. São tremidas, demasiado escuras ou demasiado claras, mostram a passagem dos corpos no espaço de fotografias feitas com uma velocidade baixa demais para a velocidade do objecto que fotografam. Contudo, elas captam aquilo a que Edwin Denby chama uma "graça inconsciente e uma espontânea animação", permitem "sentir uma companhia inteira a dançar", e dão a entender aquilo "que numa coreografia transforma uma lição em dança". Alexey Brodovitch, como referem os textos que integram a presente edição, parece fotografar como se estivesse não a trabalhar como o conhecido e exigente profissional que era, mas a fotografar memórias, a visitar pessoas e situações que o levam de novo para a 


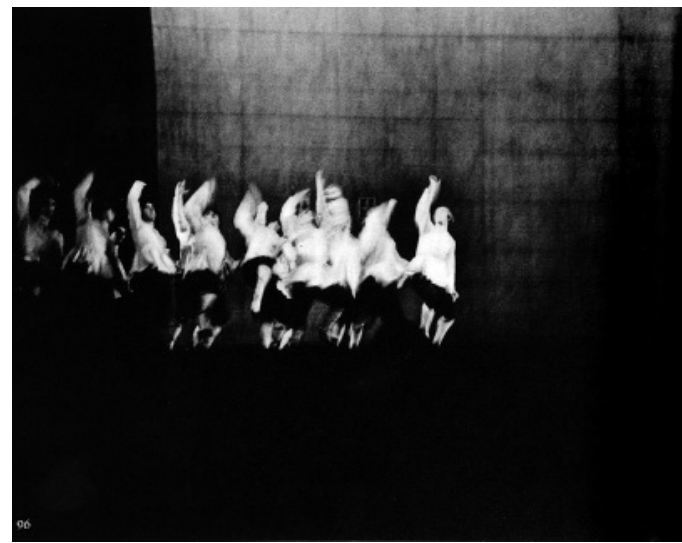

Rússia da sua infância. Para Kerry William Purcell, que escreveu a apresentação da presente edição, as fotografias de Alexey Brodovitch em Ballet remetem para "uma fantasmagoria da memória" tanto como para "a fluidez do tempo no inconsciente".

Aquilo que faz de Ballet um caso particular no universo das fotografias de dança provém, justamente, daquilo que foram os erros de Brodovitch. Aquilo que parecia inaceitável é percebido por Alexey Brodovitch como aquilo que irá ser a matéria das suas fotografias e do seu livro. Ele manipula os negativos no estúdio, e acentua os erros. Os escuros são escurecidos, os brancos são aclarados, os contrastes são instrumentalizados, os resultados são inesperados, se bem que desejados. A imprecisão material das fotos parece replicar o trabalho complexo da memória, e, como escreve Purcell, as marcas do movimento no papel permitem fixar não um movimento analítico, como fizeram Edward Muybridge ou Etienne-Jules Marey, mas prosseguir com o trabalho de fotógrafos como o futurista Anton Giulio Bragaglia e a sua "imagem desfocada" utilizada para captar o movimento de acordo com a sua ideia de "fotodinamismo".

Ballet começa com o título e créditos num cuidado e elaborado grafismo, com fotografias que remetem para os momentos de preparação e espera imediatamente anteriores ao início do espectáculo, e com a lista das coreografias fotografadas. Os onze títulos estão impressos numa só página, e formam um extraordinário painel gráfico. A variedade que esta sequência de palavras apresenta parece indicar e prenunciar a variedade que as fotografias procuram captar em cada uma das produções: Les noces, Les cent baisers, Symphonie fantastique, Le tricorne, Boutique fantasque, Cotillion, Choreartum, Septième symphonie, Le lac des cygnes, Les sylphides,

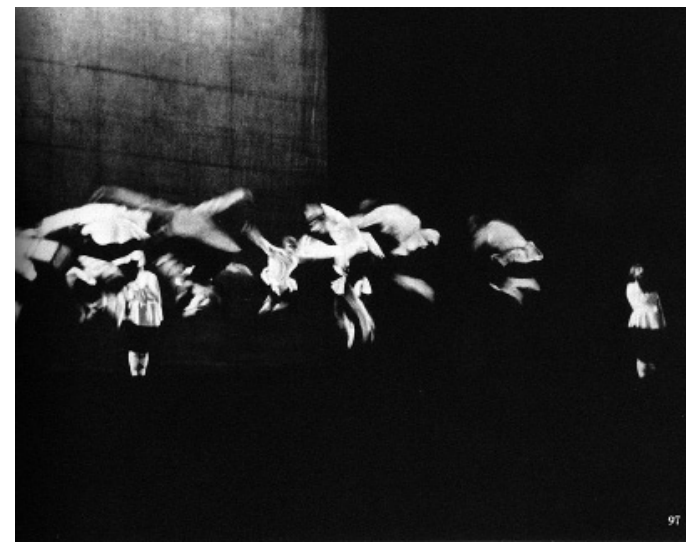

Concurrence, onze tipos de letras, onze maneiras de recordar e de sugerir aquilo que os nomes referem. No início, fotografias de bailarinos a prepararem-se sugerem incontornável e imediatamente o carácter dramático, teatral e dinâmico das representações; os lugares e as dimensões temporais começam a entrar, desde o início do livro, na teia de relações que estão na origem de toda a representação. As fotos de Les cent baisers permitem sobrepor, ler em simultâneo, as referências ao mundo da dança clássica, a vertigem do espectáculo e do movimento, a indecifrabilidade profunda de toda a obra de arte, as referências culturais a uma arte canonizada em imagens (Degas, por exemplo). As fotografias de Le lac des cygnes remetem para o ambiente profundamente clássico do ballet, tanto como para a dimensão meramente material, técnica, quase artesanal que está por detrás (detrás?) de todo o espectáculo e, simultaneamente, de todo o mecanismo de representação. Cotillion, no final do livro, sugere um universo totalmente diferente, de uma ironia ligeiramente inquietante, frivola e fortemente codificada no seu aparente abandono. Os fios e outros objectos que enchem os palcos, e que ninguém no auditório vê, coexistem com os artistas não identificáveis que agradecem, no final, numa sugestão, já fora da peça, do mesmo movimento e da mesma excitação que presidiram, e que presidem, a toda a performance.

Ballet foi recriado, em 2011, pela editora norteamericana Errata, que fotografou todo o livro e acrescentou breves mas incisivos textos: uma análise da obra por Kerry William Purcell, uma ficha sobre aspectos técnicos desta edição e uma breve biografia de Alexey Brodovitch. Inclui ainda fotos de negativos (alguns dos poucos que escaparam aos dois incêndios que destruíram grande parte da obra de Brodovich) e uma fotografia do autor, 


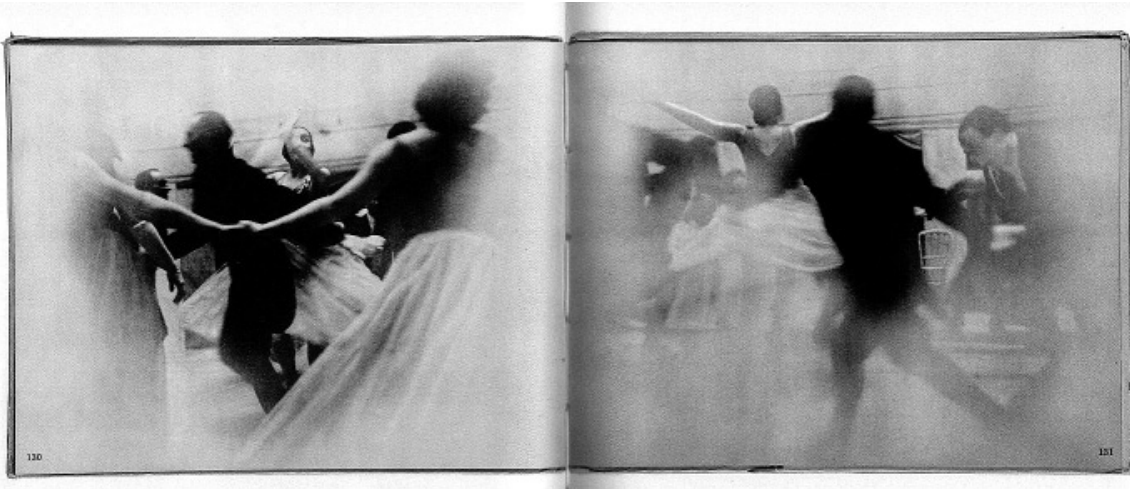
plawe 6 ?
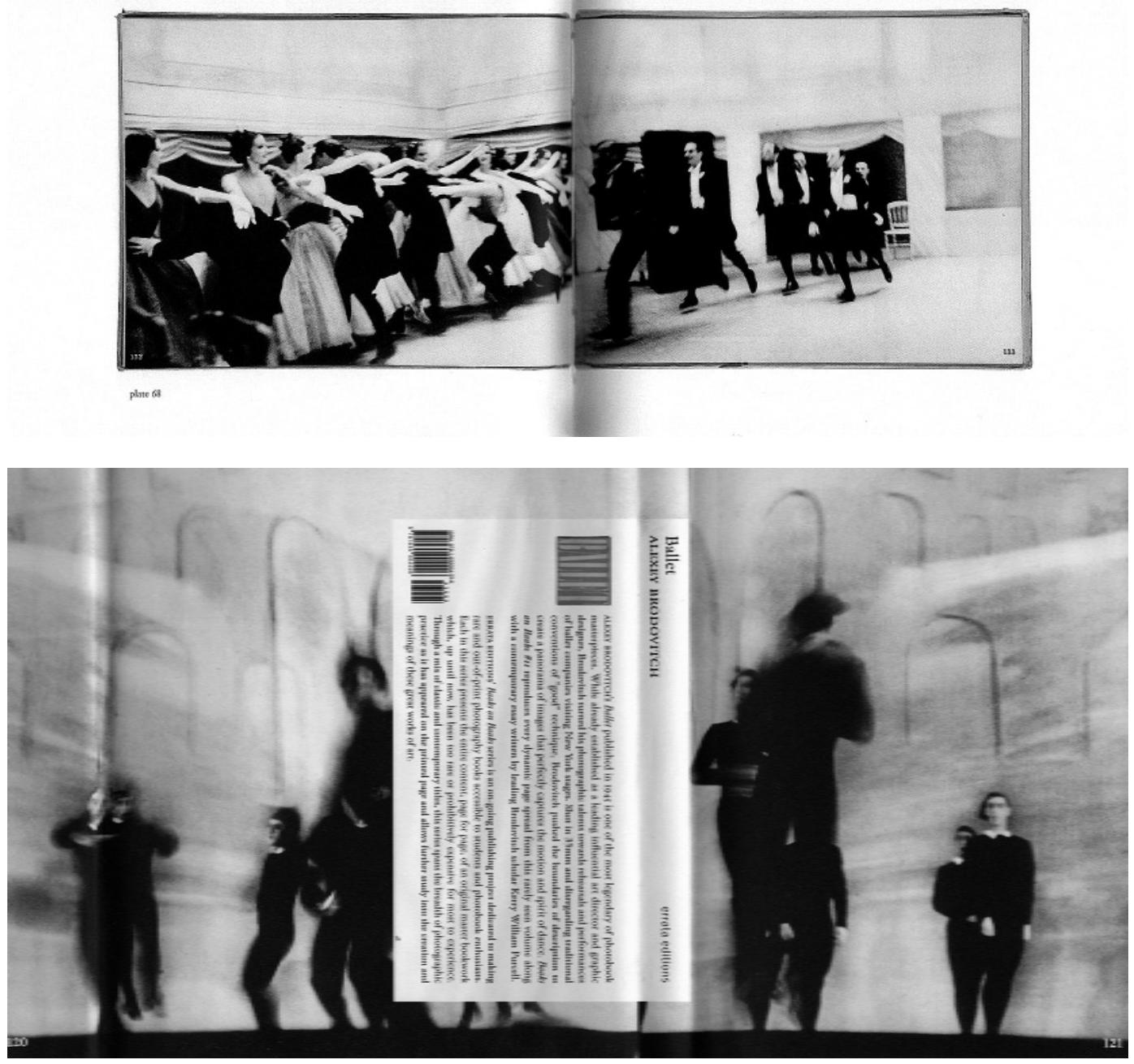

na sua casa na Pensilvânia, da autoria de Edward Kasper. Trata-se de um trabalho que nunca será demais apreciar, e que integra uma política da editora: a de tornar acessiveis obras de grande interesse e valor, mas dificeis de consultar. Trata-se, ainda, de dar a conhecer ao público contemporâneo um marco importante na história da fotografia de espectáculos, nomeadamente num caso que levanta, de maneira útil e pertinente, reflexões sobre o carácter da imagem fotográfica na sua relação com o espectáculo vivo. 0 carácter documental da fotografia de cena é aqui, mais uma vez, o cerne de uma reflexão que implica a colocação dessa fotografia no universo daquilo que parece documentar, ou que documenta realmente. Memória, lembrança, souvenir ou documento, trata-se aqui de considerar estas fotografias, cada uma por si e no seu conjunto, como emergência de uma poética, tal como cada obra referida - documentada - se estrutura de acordo com poéticas, linhas dramatúrgicas, principios condutores ou "ideias fortes". Ballet é, assim, um documento, um objecto artístico e motivo de reflexão sobre o estatuto da imagem fotográfica em geral, e da sua relação com o espectáculo, em particular.

\section{Referência bibliográfica}

BRODOVITCH, Alexey (2011), Ballet, New York, NY, Errata Editions, 142 pp. (www.errataeditions.com) 